\title{
Alkaline Phosphatase Activity in Plasma and Liver of Rats Submitted to Chronic Exposure to Fluoride
}

\author{
Mileni da Silva Fernandes, Flávia Godoy Iano, Vivian Rocia, Marcela Mitsuko Yanai, \\ Aline de Lima Leite, Tatiana Almeida Furlani, Marília Afonso Rabelo Buzalaf and \\ Rodrigo Cardoso de Oliveira* \\ Departamento de Ciências Biológicas; Faculdade de Odontologia de Bauru; Universidade de São Paulo; Al. \\ Octávio Pinheiro Brisolla, 9-75; 17012-901; Bauru - SP - Brasil
}

\begin{abstract}
The aim of this study was to compare the effect of fluoride $(F)$ on alkaline phosphatase activity in the liver and plasma of the rats. Four groups of male Wistar rats $(n=6)$, which received drinking water containing 5,15 or 50 ppm $F$ or deionized water (control) throughout the experiment were included in the study. The animals were euthanized and had their tissues and blood plasma collected for the analysis of fluoride and alkaline phosphatase. There was an increase in $F$ concentration in most tissues in the animals treated with higher F concentrations, except for the heart. The alkaline phosphatase assay showed an increase in the activity in the liver and blood plasma of the animals treated with fluoride concentrations of 15 and $50 \mathrm{ppm}(\mathrm{p}<0.05)$. This study suggested that $F$ at a concentration of 50 ppm in drinking water promotes increased the activity of alkaline phosphatase in the liver and blood plasma.
\end{abstract}

Key words: alkaline phosphatase, fluoride, liver, kidney

\section{INTRODUCTION}

The enzymes phosphatases are hydrolases whose substrates are phosphomonoesteres which are widely distributed in the nature and have been found in the animals (Galka et al., 1980; Lawrence and van Etten 1981), plants (Ferreira et al., 1999) and microorganisms (Gonzalez et al., 1993). One of the main groups of the family of phosphatases are alkaline phosphatases (Harrison et al., 1999), which are one of most widely used as indicators of hepatobiliary disease and when the serum levels are elevated frequently indicate hepatic damages (Renner and Dällenbach, 1992).
Fluoride has been used worldwide as this element has comproved efficacy on the prevention of dental caries (Whitford, 1996). It has also been used in the treatment of osteoporosis (Haguenauer et al., 2000). There is no doubt that the addition of fluoride in public water supplies and the use of fluoride dentifrice is an effective collective measure in dental caries prevention (Mullenix et al., 1995). However, this wide application of the ion can lead the population to exposure to high fluoride concentrations. Its effects when absorbed into specific tissues or organs such as heart, liver and kidneys remain unclear. Moreover, reports of intoxication in the humans suggest that chronic exposure to fluoride can affect the activity of

*Author for correspondence: rodrigocardoso@usp.br 
enzymes involved in important physiological processes in the tissues (Hallanger, 2007). Some reports have shown that fluoride can change the activity of some enzymes, including alkaline phosphatase (Shanthakumari et al., 2004). Liver diseases with the primary lesion of parenchyma cells normally show only moderate elevations in alkaline phosphatase activity (Touitou and Bogdan 1988). So far, some works show controversial results about fluoride effects, but few of them correlate these alterations caused by this ion in different level (some tissue and enzymes) or within the same protocol (sometimes they appear in in vitro or in vivo studies).

Therefore, the aim of this study was to assess the changes in the activity of alkaline phosphatase in the plasma and liver of the rats chronically exposed to fluoride in the drinking water. The effects of this ion on the weight of various organs of these animals were also assessed.

\section{MATERIALS AND METHODS}

\section{Animals and treatment}

The study was conducted according to the standards recommended by the Brazilian College of Animal Experimentation (COBEA), after approval of the Animal Committee of Bauru School of Dentistry, University of São Paulo (USP), FOB-USP (Number 20/2006).

Twenty-four male Wistar rats (Rattus norvegicus), from the Central Vivarium of Bauru Dental School - University of São Paulo (FOB-USP) were included. After weaning (20 days old), the animals were randomly divided into four groups $(\mathrm{n}=6 \mathrm{per}$ group) according to the concentration of fluoride given during the entire experimental period (60 days). Group I received deionized water (control), while groups II, III and IV received the water containing 5, 15 or $50 \mathrm{ppm}$ of fluoride, respectively. Throughout the experimental period, the animals were kept in the cages receiving the food and water ad libitum. The food used was AIN-93 (Reeves et al., 1993) with low fluoride concentration $(<2 \mathrm{ppm})$, since in previous reports it was observed that the commercial diets might have high fluoride concentrations (Buzalaf et al., 2004; Buzalaf et al., 2005; Carvalho et al., 2006), which could affect the results.

\section{Euthanasia and sample collection}

The animals were sedated and anesthetized with a mixture of Anasedan ${ }^{\circledR}$ (xylazine) and Dopalen ${ }^{\circledR}$ (ketamine base) in a proportion of 1:1 (bulk). This mixture $(0.2 \mathrm{~mL})$ was administered to each animal intramuscularly. Then, a blood sample was collected from the heart into a lightly heparinized syringe. Plasma was stored for the analysis of fluoride and alkaline phosphatase. The collected organs (left kidney, liver and heart) were washed with the cold saline solution, weighed and stored ($\left.80^{\circ} \mathrm{C}\right)$.

\section{Homogenization of samples and analysis of alkaline phosphatase}

The homogenization of liver samples for the assay of alkaline phosphatase were made according to Granjeiro et al. (1997).

\section{Analysis of alkaline phosphatase activity in blood plasma and liver}

Alkaline phosphatase assay was done in the plasma and liver, using a commercial kit, according to the manufacturer's instructions (Doles® Reagent and laboratory Equipment Ltd., Goiânia, Brazil). The absorbance was read at 410 $\mathrm{nm}$ in a spectrophotometer (ULTROSPEC II, Pharmacia). The results were expressed in UI/L. Each UI/L equals to $0.01667 \mu \mathrm{kat} / \mathrm{L}$.

\section{Homogenization of samples for fluoride analysis}

The left kidney samples were homogenized (model MA 102, Marconi, Goiânia, Brazil) using a proportion of $0.1 \mathrm{~g}$ of tissue to $500 \mu \mathrm{L}$ of deionized water. The same procedure was performed for the samples of liver and heart, except for the proportion tissue to water. For the liver, it was $0.2 \mathrm{~g}$ of tissue to $500 \mu \mathrm{L}$ of deionized water, while for the heart, it was $0.1 \mathrm{~g}$ of tissue to $1000 \mu \mathrm{L}$ of water.

\section{Fluoride analysis in plasma}

The analysis of fluoride concentrations in the plasma was made by the HMDS (hexamethyldisiloxane) facilitated diffusion (Taves method (Taves, 1968), as modified by Whitford (, 1996) using an ion-specific electrode (Orion Research, Model 9409, Cambridge, USA) and a miniature calomel electrode (Accumet, \#13620-79), both coupled to a potentiometer (Orion Research, Model EA 940, Cambridge, UDA). 
Deionized water $(2.0 \mathrm{~mL})$ was placed in the bottom of a non-wettable diffusion dish (Falcon, 1007) along with the plasma. The trapping solution, $50 \mu \mathrm{L}$ of $0.05 \mathrm{M} \mathrm{NaOH}$, was placed in five drops on the inside of the lid of the dish. The periphery of the lid was ringed with vaseline and sealed to the bottom of the dish. Then $2.0 \mathrm{~mL}$ of $3.0 \mathrm{M} \mathrm{H}_{2} \mathrm{SO}_{4}$ saturated with HMDS were added to the bottom through a small hole previously burned into the lid with a soldering iron. The hole was immediately sealed with vaseline. During the diffusion process, which continued overnight at room temperature, the solutions were swirled at 45 rpm on a rotary shaker. The next day, the lid was removed and inverted and the trapping solution was buffered to $\mathrm{pH} 5.0$ with $25 \mu \mathrm{L}$ of $0.20 \mathrm{M}$ acetic acid. The final volume was then adjusted to $75 \mu \mathrm{L}$ by the addition of deionized water using a fixed volume pipettor. The fluoride and reference electrodes were placed in contact with the solution with gentle agitation until a stable $\mathrm{mV}$ reading was obtained. Fluoride standards $(0.019,0.095,0.190$, $0.950,1.900$ and $4.750 \mu \mathrm{g}$ fluoride) were prepared in triplicate and diffused in the same manner as the plasma samples. In addition, non-diffused standards were prepared with the same reagents and in the same proportions as those used to prepare the diffused standards and samples. The non-diffused standards were made to have exactly the same fluoride concentrations as the diffused standards. Comparison of the $\mathrm{mV}$ readings demonstrated that the fluoride in the diffused standards had been completely trapped and analyzed (recovery > 99\%). The $\mathrm{mV}$ potentials were converted to $\mu \mathrm{g} F$ using a standard curve with a coefficient correlation of $r \geq 0.99$.

\section{Fluoride analysis in kidney, liver and heart}

The analysis of fluoride concentrations in the kidney, liver and heart, were made by the HMDS- facilitated diffusion, as described for the plasma, except for pre-diffusion, which was not performed in this case.

\section{Statistical analysis}

The software GraphPad Instat version 3.0 for the Windows (Graph Pad Software, San Diego, USA) was used. Data were initially checked for the normality (Kolmogorov and Smirnov test) and homogeneity (Bartlett test). For the heart and kidney weight, these criteria were satisfied and the data were analyzed by the ANOVA. For alkaline phosphatase in the liver and fluoride concentration in the plasma and liver, data had normal distribution, but there was no homogeneity of standard deviations. They were then analyzed by the ANOVA after logarithmic transformation. Tukey's test was used as post hoc for the ANOVA. Data related to liver weight were not homogenous and were then analyzed by a nonparametric test (Kruskal-Wallis). The level of significance in all the cases was set at $5 \%$.

\section{RESULTS}

\section{Organs weight}

In general, there was a decrease in the weight of the organs with the increase in fluoride concentrations given to the animals (Table 1). Significant differences were observed for the liver $(\mathrm{KW}=12.178)$ between the control group and the group treated with $50 \mathrm{ppm}$ F. Significant differences were also detected for the kidney $(\mathrm{F}=$ 4.654). Control group was significantly different from the groups that received 15 and $50 \mathrm{ppm}$ F. Significant differences were also found for the hearts $(F=6.675)$. In this case, group III was significantly different from the groups II and IV.

Table 1 - Weight samples (g) of kidney. liver and heart to the control group (I). 5 ppm (II). 15 ppm (III) and 50 ppm (IV).

\begin{tabular}{cccc}
\hline \multirow{2}{*}{ Groups } & \multicolumn{3}{c}{ Weight $(\mathbf{g})$} \\
\cline { 2 - 4 } & Kidney & Liver & Heart \\
\hline I & $0.89^{\mathrm{a}}(0.08)$ & $7.32^{\mathrm{a}}(0.66)$ & $0.84^{\mathrm{a} . \mathrm{b}}(0.13)$ \\
II & $0.83^{\mathrm{a} . \mathrm{b}}(0.11)$ & $6.65^{\mathrm{a} . \mathrm{b}}(0.88)$ & $0.82^{\mathrm{a}}(0.10)$ \\
III & $0.87^{\mathrm{a}}(0.12)$ & $6.53^{\mathrm{a} b \mathrm{~b}}(0.80)$ & $0.98^{\mathrm{b}}(0.06)$ \\
IV & $0.68^{\mathrm{b}}(0.09)$ & $5.55^{\mathrm{b}}(0.17)$ & $0.74^{\mathrm{a}}(0.05)$ \\
\hline
\end{tabular}

\footnotetext{
$\overline{\mathrm{a}, \mathrm{b}}$ distinct letters at the same column indicate statistically significant difference $\mathrm{p} \leq 0.05$
}

() standard deviation 


\section{Analysis of fluoride concentration}

The analysis of the fluoride concentration in the plasma, kidney, liver and heart can be seen in Table 2. There was an increase in the plasma fluoride concentrations with the increase in fluoride concentration administered in the drinking water $(F=36.65)$. Significant differences were found between all the groups, except for the group II when compared with the control group. The same trend was seen for the liver $(\mathrm{F}=44.09)$. There was a significant difference between all the groups, except for the group III compared to group IV.

As for the kidney, significant differences were detected among the groups $(\mathrm{KW}=15.891)$ and a dose-response was also seen. In this case, groups I and II presented significantly lower fluoride levels when compared to group IV.

Table 2 - Fluoride concentration in plasma $(\mu \mathrm{g} / \mathrm{mL})$. kidney. liver and heart $(\mu \mathrm{g} / \mathrm{g})$ for the control group (I). 5 ppm (II). 15 ppm (III) and 50 ppm (IV).

\begin{tabular}{ccccc}
\hline \multirow{2}{*}{ Groups } & \multicolumn{4}{c}{ Fluoride Concentration } \\
\cline { 2 - 5 } & Plasma & Kidney & Liver & Heart \\
\hline I & $0.034^{\mathrm{a}}(0.01)$ & $0.080^{\mathrm{a}}(0.04)$ & $0.013^{\mathrm{a}}(0.005)$ & $0.121^{\mathrm{a}}(0.045)$ \\
II & $0.039^{\mathrm{a}}(0.008)$ & $0.070^{\mathrm{a}}(0.008)$ & $0.026^{\mathrm{b}}(0.005)$ & $0.097^{\mathrm{a}}(0.046)$ \\
III & $0.087^{\mathrm{b}}(0.02)$ & $0.144^{\mathrm{a} b}(0.03)$ & $0.066^{\mathrm{c} d}(0.033)$ & $0.084^{\mathrm{a}}(0.014)$ \\
IV & $0.143^{\mathrm{c}}(0.03)$ & $0.366^{\mathrm{b}}(0.06)$ & $0.095^{\mathrm{d}}(0.015)$ & $0.081^{\mathrm{a}}(0.015)$ \\
\hline
\end{tabular}

$\overline{\mathrm{a}, \mathrm{b}}$ distinct letters at the same column indicate statistically significant difference $\mathrm{p} \leq 0.05$

() standard deviation

\section{Analysis of alkaline phosphatase}

Regarding the enzymatic activity of alkaline phosphatase in the plasma, group IV presented largest activity (9.30 IU / $\mathrm{L} \pm 0.22 \mathrm{IU} / \mathrm{L}$ ) which was significantly different from all the other groups $(F=852.13)$. However, for the liver, the highest activity was found for the group III (15.756 IU / L $\pm 7.55 \mathrm{IU} / \mathrm{L}$ ) and the lowest for the control group (7.069 IU / L $\pm 2.19 \mathrm{IU} / \mathrm{L}$ ). These groups differed significantly from each other $(\mathrm{F}=5.536)($ Table 3$)$.

Table 3 - Alkaline phosphatase activity (UI / L) in plasma and liver in the control group (I). 5 ppm (II). 15 ppm and $50 \mathrm{ppm}(\mathrm{IV})$.

\begin{tabular}{ccc}
\hline \multirow{2}{*}{ Groups } & \multicolumn{2}{c}{ Alkaline Phosphatase Activity } \\
\cline { 2 - 3 } & Plasma & Liver \\
\hline I & $1.070^{\mathrm{a}}( \pm 0.29)$ & $7.069^{\mathrm{a}}( \pm 2.19)$ \\
II & $0.667^{\mathrm{a}}( \pm 0.17)$ & $11.419^{\mathrm{a}}( \pm 1.419)$ \\
III & $1.091^{\mathrm{a}}( \pm 0.50)$ & $15.756^{\mathrm{a} . b}( \pm 7.55)$ \\
IV & $9.30^{\mathrm{b}}( \pm 0.22)$ & $9.37^{\mathrm{a}}( \pm 3.02)$ \\
\hline
\end{tabular}

${ }^{\mathrm{a}, \mathrm{b}}$ distinct letters at the same column indicate statistically significant difference $\mathrm{p} \leq 0.05$

Each UI / L equals $0.01667 \mu \mathrm{kat} / \mathrm{L}$.

\section{DISCUSSION}

The deleterious effects of fluoride have been studied in the last decades due to the widespread and inadvertent use of this element, causing problems such as dental fluorosis and osteopetrosis. Additionally, fluoride might have systemic toxic effects in other tissues when ingested in levels higher than optimal (Buzalaf et al., 2004; Buzalaf et al., 2005; Leite et al., 2008; Kobayashi et al, 2009).

Plasma is an important indicator of fluoride levels in the body in both acute (Buzalaf et al., 2004;
Pessan et al., 2005) and chronic (Carvalho et al., 2006) exposures. The results of this study were in agreement with previous studies that demonstrated an increase of fluoride concentration in the plasma due to the increase in the chronic intake of fluoride (Carvalho et al., 2006). This was expected, since plasma was the central compartment involved in the metabolism of fluoride, where fluoride passed for its subsequent distribution and elimination, since there was no homeostasis. Whitford (1996) has reported that the fraction of ionic plasma fluoride increases with the intake and, in addition, when the entry of fluoride in the plasma exceeds 
the degree of removal, plasma concentrations also increase. In this work, the group treated with 5 ppm of fluoride in the water did not present fluoride levels significantly different from the control group, in agreement with other studies (Kobayashi et al., 2009). This could be explained by the incorporation of part of fluoride into mineralized tissues, while higher doses of fluoride could saturate the effect of its uptake into mineralized tissues (Ekstrand et al., 1977).

Krishnamachari (1986) observed severe damage in the liver caused by the chronic ingestion of fluoride. The reduction in the size of this organ upon exposure to fluoride can be one of the factors responsible for the changes in the normal function, causing the observed damage. Other studies have found fluoride accumulation in the liver of the rats under treatment with fluoridated water at 5 and 25 ppm for 12 weeks (Inkielewitz and Krechniak 2003; Inkielewitz et al., 2006). The presence of fluoride in small concentrations in the liver ( 1 to $10 \mathrm{mM}$ ) can significantly interfere on the activity of certain enzymes, such as lactate dehydrogenase (increase), glycogen phosphorylase (increase), lipase (inhibition), enolase (inhibition) and glycogen synthase (inhibition). Negative (Strunecka et al., 2007) effects on the liver function were also suggested in this study in the group treated with the highest fluoride concentration $(50 \mathrm{ppm})$ due to the alterations observed in the plasma alkaline phosphatase activity. This finding was suggestive of the changes in liver function, since the activity of this enzyme could be used as a diagnostic tool for the damages in human liver (Limdi and Hyde 2003). The lower weight of the liver in the animals treated with $50 \mathrm{ppm}$ fluoride supported the changes in the liver function induced by high levels of chronic fluoride intake. But on the other hand, Kobayashi et al. (2009) described no differences on the total body weight of the animals after 60 days of fluoride treatment (weight: 265$275 \mathrm{~g}$ ). These results (the present results and Kobayashi' results) could be an indicative that some differences caused in the tissues by fluoride had targets more specifics like enzymes, and other microscopic alterations.

One interesting finding of this study was the significant increase in the activity of alkaline phosphatase in the liver of the animals treated with $15 \mathrm{ppm} F$ when compared to the control but the lack of such increase in the group treated with 50 ppm F. This could be due to adaptive responses of the organism that are likely to occur upon exposures to high levels of fluoride for a long time. It was possible that if the treatment with 50 ppm fluoride had been conducted for a shorter time, the increase of alkaline phosphatase activity in the liver would had seen, before the organism have had time to produce the adaptive response.

The increased fluoride concentrations in the kidneys of the animals treated with 15 and $50 \mathrm{ppm}$ were expected, since kidneys were responsible for the excretion of fluoride (Whitford, 1996). Fluoride at $50 \mathrm{ppm}$ was also capable to reduce the weight of the kidneys when compared to the control group, which was consistent to the findings of other studies demonstrating a nephrotoxic effect of fluoride at high doses (Kobayashi et al., 2009; Strunecka et al., 2007), with an altered proteomic profile, hydropic degeneration in epithelial cells and vascular congestion (Kobayashi et al., 2009; Oncu et al., 2004). The hydropic degeneration can cause shrinkage of glomeruli (Oncu et al., 2004), thus leading to a decrease in the weight of the organ.

Heart unlike kidney and liver did not show substantial difference in fluoride concentrations between the groups. There was evidence of a protective effect of the components of the antioxidant system in the heart, thus preventing some lesions (Shan et al., 1990). Thus, this organ seemed to be more resistant to the effects of fluoride. Studies have shown the changes of enzymes in various organs such as liver, kidneys and pancreas upon exposure to fluoride, but were unable to detect substantial changes in the heart, except for an alteration in potassium and calcium channels (Strunecka et al., 2007).

The animals treated with $5 \mathrm{ppm}$ of fluoride in the drinking water, which was correspondent to a dose of $1 \mathrm{ppm}$ in the drinking water for the humans (Dunipace et al., 1995) did not present increases in fluoride concentrations in the organs or reduction of their weight. This confirmed the security of controlled water fluoridation (0.7-1.2 ppm). These low doses of fluoride did not promote important metabolic changes in the organs such as heart and kidneys nor peak plasma levels (Carvalho et al., 2006).

Thus, it could be concluded that fluoride at a concentration of $50 \mathrm{ppm}$ in the drinking water promoted increased activity of alkaline phosphatase in the liver and plasma, besides promoting a decrease in the weight of organs such as kidneys and liver. 


\section{ACKNOWLEDGEMENTS}

This work was supported by FAPESP (Processes: 2006/06430-3 and 2007/00494-2) and CNPq (Process: 472798/2008-1). The authors thank CAPES for the concession of a scholarship to the first author.

\section{REFERENCES}

Buzalaf, M.A. et al. (2004), Nail and bone surface as biomarkers for acute fluoride exposure in rats. $J$ Anal Toxicol., 28, 249-252.

Buzalaf, M.A. et al. (2005), Bone surface and whole bone as biomarkers for acute fluoride exposure. $J$ Anal Toxicol., 29, 810-813.

Carvalho, J.G. et al. (2006), Plasma as an indicator of bone fluoride levels in rats chronically exposed to fluoride. J. Appl. Oral Sci., 14, 238-241.

Dunipace, A.J. et al. (1995), Effect of aging on animal response to chronic fluoride exposure. J. Dent. Res., 74, 358-368.

Ekstrand, J. et al. (1977), Absence of protein-bound fluoride from human and blood plasma. Arch. Oral Biol., 22, 229-232.

Ferreira, C.V. et al. (1999), Glycolytic Intermediates as Substrates of Soybean Acid Phosphatase Isoforms. Plant Science, 147, 49-54.

Galka, M. et al. (1980), Properties of low-molecularweight acid phosphatases isolated from cytosol and chromatin of rat liver. Acta Biochim Pol., 27, 281293.

Gonzalez, F.J. et al. (1993), Kinetic behaviour of a repressible acid phosphatase from the yeast Yarrowia lipolytica: a comparative study between the solubilized enzyme, the enzyme bound to cell-wall fragments and the enzyme bound to intact cells. Biochim. Biophys. Acta, 1162, 17-27.

Granjeiro, J.M. et al. (1997), Purification and characterization of a low-molecular-weight bovine kidney acid phosphatase. An. Acad. Bras. Cienc., 69, 451-460.

Haguenauer, D. et al. (2000), Fluoride for the treatment of postmenopausal osteoporotic fractures: a metaanalysis. Osteoporos Int., 11, 727-738.

Harrison, S. et al. (1999), Airway nerves and protein phosphatases. Gen Pharmacol., 32, 287-298.

Inkielewitz, I. and Krechniak, J. (2003), Fluoride content in soft tissues and urine of rats exposed to sodium fluoride in drinking water. Fluoride, 36, 263266.

Inkielewitz, I. et al. (2006), Lipid peroxidation and antioxidant enzyme activity in rats exposed to fluoride and ethanol. Fluoride, 39, 56-59.
Kobayashi, C.A. et al. (2009), Proteomic analysis of kidney in rats chronically exposed to fluoride. Chem. Biol. Interact., 180, 305-311.

Krishnamachari, K.A. (1986), Skeletal fluorosis in humans: a review of recent progress in the understanding of the disease. Prog. Food Nutr. Sci., 10, 279-314.

Lawrence, G.L. and van Etten, R.L. (1981), The lowmolecular-weight acid phosphatase from bovine liver: isolation, amino acid composition, and chemical modification studies. Arch. Biochem. Biophys., 206, 122-131.

Levy, S.M. et al. (1995), Sources of fluoride intake in children. J. Public Health Dent., 55, 39-52.

Limdi, J.K. and Hyde, G,M. (2003), Evaluation of abnormal liver function tests. Postgrad. Med. J., 79, 307-312.

Mullenix, P.J. et al. (1995), Neurotoxicity of sodium fluoride in rats. Neurotoxicol Teratol., 17, 169-177.

Oncu, M. et al. (2004), Investigation on the histopathological effects of thyroidectomy on the seminiferous tubules of immature and adult rats. Urol. Int., 73, 59-64.

Pessan, J.P. et al. (2005), Analysis of fingernails and urine as biomarkers of fluoride exposure from dentifrice and varnish in 4- to 7-year-old children. Caries Res., 39, 363-370.

Pratt, D,S, and Kaplan, M.M. (2001), Evaluation of Liver Function. In-Harrison's Principles of Internal Medicine, McGraw- Hill, pp. 1711-1715.

Reeves, P.G. et al. (1993), AIN-93 purified diets for laboratory rodents: final report of the American Institute of Nutrition ad hoc writing committee on the reformulation of the AIN-76A rodent diet. J. Nutr., 123, 1939-1951.

Shan, X.Q. et al. (1990), Glutathione-dependent protection against oxidative injury. Pharmacol Ther., 47, 61-71.

Shanthakumari, D. et al. (2004), Effect of fluoride intoxication on lipidperoxidation and antioxidant status in experimental rats. Toxicology, 204, 219-228.

Strunecka, A. et al. (2007), Fluoride interactions: From Molecules to disease. Curr. Signal Transduct Ther., 2, 190-213.

Taves, D.R. (1968), Determination of submicromolar concentrations of fluoride in biological samples. Talanta, 15, 1015-1023.

Touitou, Y. and Bogdan, A. (1988), Tumor markers in non-malignant diseases. Eur. J. Cancer Clin. Oncol., 24, 1083-1091.

Whitford, G.M. (1996), The metabolism and toxicity of fluoride. Monograph Oral Science, Medical College of Georgia, Georgia, U.S.A.

Received: March 25, 2010; Revised: December 21, 2010; Accepted: August 26, 2011. 